\title{
Survey of Interventional Pain Physicians on Bending Spinal Needles for Chronic Pain Procedures
}

\author{
Geoffrey D. Panjeton, MD, Ahmad Abdul-Rahim, DO, Penny S. Reynolds, PhD, Ajay B. Antony, MD
}

Background: Interventional pain procedures involve placement of fine-gauge spinal needles, which practitioners will frequently bend to facilitate both driving the needle through tissue, and to increase accuracy of placement at a specific spinal structure or nerve target. This bend is commonly performed by hand, leaving the proceduralist at risk for fingerstick injury, and the patient at risk of site contamination. However, few case studies have been published, and there are almost no data on physician preference or practice. Objectives: The purpose of this study was to survey interventional pain physicians on their practice of spinal needle manipulation before performing lumbar medial branch nerve blocks. Specific aims were to assess the prevalence of manual needle bending, and to determine possible associations with practitioner experience, clinical environment, and fingerstick injury.

Study Design: A survey.

Setting: Annual 2018 American Society for Interventional Pain Physicians conference in Orlando, Florida.

Methods: A convenience sample of participants were screened for eligibility and asked to voluntarily participate in a de-identified IRB-approved survey (IRB201703055). The survey consisted of 5 questions, 2 with binary answer choices and the remaining 3 with multiple answer choices. Data were collected on an iPad via Qualtrics software. Data were analyzed by descriptive statistics (counts, percentages).
Results: Of 480 interventional pain physician attendees at the conference, $154(32.1 \%)$ completed the survey. The majority $(114 / 154 ; 74 \%)$ reported 'always' bending the distal tip of spinal needles, and a further $21(14 \%)$ reported 'sometimes'; 19 $(12 \%)$ said they do not bend their needles. Only $25(18 \%)$ respondents used an instrument to bend their needles; $112(82 \%)$ bend their needles by hand. Eight respondents (6\%) reported a fingerstick injury while bending a spinal needle, one while using an instrument, and 7 during a manual bend. Approximately half of respondents had been practicing for greater than 15 years; $78 \%$ work in a private practice environment.

Limitations: Due to the setting, the recruitment method presents the possibility of selection bias. Furthermore, although the response rate may appear low, it is higher than similarly performed studies.

Conclusions: Spinal needle manipulation is common prior to performing interventional pain procedures, and most spinal needle manipulations are performed by hand. Rate of fingerstick injury was low in this sample, but cannot be evaluated without comparative data. Factors to be considered in a subsequent study are the effects of needle bend variability relative to practitioner experience and alternative means of needle manipulation.

Key words: Interventional pain procedures, spinal needles, facet joint injections, needle bending, fingerstick injuries

From : Department of Anesthesiology, University of Florida, Gainesville, FL

Author for correspondence: Geoffrey D. Panjeton, MD

Address: Department of Anesthesiology, University of Florida, PO Box 100254, Gainesville, FL 32610-0254

E-mail: gpanjeton@anest.ufl.edu

Disclaimer: There was no external funding in the preparation of this manuscript. Conflict of interest: Each author certifies that he or she, or a member of his or her immediate family, has no commercial association (i.e., consultancies, stock ownership, equity interest, patent/licensing arrangements, etc.) that might pose a conflict of interest in connection with the submitted manuscript. 
The lifetime prevalence of spinal pain has been reported as 54 to $80 \%$ and low back pain specifically ranges between 15 to $45 \%$ of patients (1). The facet (or zygapophyseal) joint is reported as being the underlying pain generator in 15 to $45 \%$ of patients with low back pain (1). Interventions to address this pain generator include injections targeting the medial branch nerve innervating the facet joint. This procedure is the second most commonly performed interventional procedure for chronic pain (2). This procedure, like many other interventional pain procedures, requires fluoroscopic guidance to place fine-gauge spinal needles targeting a specific spinal structure or nerve. Frequently, practitioners will bend the tip of the spinal needle to facilitate both driving the needle through tissue, and to increase the accuracy of placement. This bend is commonly performed by hand. One reference to this bend is found in the literature, however no mention is made of means by which to apply the bend and there are almost no data on physician preference or practice (3). Also concerning is that this practice leaves the proceduralist at risk for fingerstick injury, and the patient at risk of site contamination. Currently, there is no literature on the prevalence of fingerstick injuries amongst interventional pain physicians.

The purpose of this study was to survey interventional pain physicians on their practice of spinal needle manipulation before performing lumbar medial branch nerve blocks. Specific aims were to assess the prevalence of manual needle bending, and determine possible associations with practitioner experience, clinical environment, and fingerstick injury.

\section{METHODS}

A 5-question survey (Appendix A) was created with input from anesthesiology residents, pain management attending physicians and fellows in training, and a statistician to identify practice habits related to spinal needle manipulation before performing lumbar medial branch nerve blocks. This survey was submitted along with a study proposal to the University of Florida Institutional Review Board and was approved with an exemption of written informed consent (IRB201703055). Literature review did not reveal any prior surveys with this objective, as such no appropriate validation tool was available. The survey consisted of 2 questions with binary answer choices and 3 other questions with multiple answer choices. This survey was made available on an iPad via the Qualtrics software (Qualtrics, Provo, UT) and physicians attending the 2018 annual American Society for Interventional Pain Physicians conference in Orlando, FL from March 16th to 18th, 2018 were asked to participate in the survey during the conference. Attendees were approached and screened to determine whether they were interventional pain physicians, including fellows in training, prior to proceeding with survey completion.Qualtrics software collected the responses, tallied the results, and generated figures reflecting the data.

\section{RESULTS}

Conference organizers reported that 480 interventional pain physicians attended the annual conference. Of these eligible participants, 154 (32.08\%) completed the survey. The results are presented in tabulated format in Table 1. The majority $(n=114$; $74.03 \%$ ) reported 'always' bending the distal tip of spinal needles, and a further $21(13.64 \%)$ reported 'sometimes'. Only 19 participants (12.34\%) said they do not bend their needles. Of those who do bend their needles, 25 (18.25\%) respondents used an instrument to bend their needles and 112 (81.75\%) bend their needles by hand. Overall, 8 respondents $(5.63 \%)$ reported a fingerstick injury while bending a spinal needle, one while using an instrument and 7 while using their hand. There was no apparent relationship between time in practice or type of practice setting, and the occurrence of a fingerstick injury, 3 were in their first 5 years of practice, one had been in practice between 6 to 10 years and another 4 had been in practice greater than 15 years. Similarly, there was no relationship with practice type and fingerstick injury as 5 were in private practice and the other 3 were in a hospital-based practice. Approximately half $(51.95 \%, n=80)$ of respondents had been practicing for greater than 15 years; $77.92 \%(n=120)$ work in a private practice environment.

\section{DISCUSSION}

This survey provides a glimpse into the current practice of spinal needle manipulation for lumbar facet joint injections. Literature searches do not reveal any 
references to this maneuver, despite its seemingly prevalent adoption. The results of this survey seem to indicate a predilection towards applying spinal needle manipulation by hand which poses a theoretical risk of fingerstick injury and needle contamination. Although this was not reflected by the survey responses, other studies reference fingerstick injury rates between 3 and $6.9 \%$ (4). Furthermore, one study mentions that of the injuries that were recorded, $75 \%$ were unnoticed by the injured(5). It is possible, therefore, that survey respondents may not have been aware of the injuries they sustained.

Another issue highlighted by the results of the survey is the use of an external instrument to manipulate the spinal needle. From the respondents, $18.25 \%$ $(n=25)$ reported using an external instrument to manipulate the needle. Commonly, this was reported to either be the sheath in which the needle is packaged. This practice can be problematic for several reasons. It is often difficult to secure the needle tip in the large sheath space, resulting in bends applied at unpredictable and imprecise angles and points along the needle shaft. Common practice is to bend the needle away from the bevel, however when using the needle sheath, it can be difficult to control the needle such that the desired bend direction is achieved, and oblique bends can occur.

There are numerous limitations to this observational study of a convenience sample including the possibility of selection bias. In our survey, eligible participants were screened as able during the conference, however many were uninterested in participating in the survey. Thus, only those who were interested, ultimately completed the survey. Obtaining adequate responses to surveys can often be difficult and often dampen the utility of the results. Our response rate of $32.1 \%$ is higher than other recently published surveys of practice habits amongst physicians related to pain management $(6,7)$.
Table 1. Survey questions and results.

\begin{tabular}{|c|c|c|}
\hline Question & Answer Choice & Percentage \\
\hline \multirow{3}{*}{$\begin{array}{l}\text { Do you employ any } \\
\text { manual manipulation or } \\
\text { "bend" at the distal tip } \\
\text { of your spinal needle for } \\
\text { procedures? }\end{array}$} & Yes & $74.03 \%$ \\
\hline & Sometimes & $13.64 \%$ \\
\hline & No & $12.34 \%$ \\
\hline \multirow{2}{*}{$\begin{array}{l}\text { If you place a bend on } \\
\text { your needles, how do you } \\
\text { employ the bend? }\end{array}$} & By hand & $81.75 \%$ \\
\hline & Using an instrument & $18.25 \%$ \\
\hline \multirow{2}{*}{$\begin{array}{l}\text { Have you ever suffered } \\
\text { injury (fingerstick) while } \\
\text { bending the spinal needle } \\
\text { manually? }\end{array}$} & Yes & $5.63 \%$ \\
\hline & No & $94.37 \%$ \\
\hline \multirow{4}{*}{$\begin{array}{l}\text { 4. How long have you } \\
\text { been practicing as an } \\
\text { interventional pain } \\
\text { physician? }\end{array}$} & $0-5$ years & $19.48 \%$ \\
\hline & $6-10$ years & $12.34 \%$ \\
\hline & $10-15$ years & $16.23 \%$ \\
\hline & $>15$ years & $51.95 \%$ \\
\hline \multirow{4}{*}{$\begin{array}{l}\text { 5. What type of practice } \\
\text { best represents your work } \\
\text { setting? }\end{array}$} & Academic institution & $7.14 \%$ \\
\hline & Private practice & $77.92 \%$ \\
\hline & Hospital based practice & $10.39 \%$ \\
\hline & Multispecialty group & $4.55 \%$ \\
\hline
\end{tabular}

As interventional pain management becomes an increasingly important field in a society battling an opioid addiction crisis, it is important to maximize the safety and efficacy of these procedures. Facet joint injections are a very common procedure and working to standardize these procedures to minimize the risks to both patients and practitioners is crucial. Spinal needle manipulation can be beneficial in improving the efficiency of these procedures; however, care must be taken to avoid personal injury or instrument contamination. This survey provides a glimpse into the practice habits of a select population of interventional pain proceduralists. Factors to be considered in a subsequent study are the effects of needle bend variability relative to practitioner experience and alternative means of needle manipulation. 


\section{REFERENCES}

1. Boswell MV, Trescot AM, Datta S, et al. Interventional techniques: Evidence-based practice guidelines in the management of chronic spinal pain. Pain Physician 2007; 10:7-111.

2. Cohen SP, Doshi TL, Constantinescu OC, et al. Effectiveness of lumbar facet joint blocks and predictive value before radiofrequency denervation: The Facet Treatment Study (\{FACTS\}), a randomized, controlled clinical trial. Anesthesiology 2018; 129:517-535.

3. lannuccilli JD, Prince EA, Soares GM. Interventional spine procedures for management of chronic low back pain-a primer. Semin Intervent Radiol 2013; 30:307-317.

4. Tokars JI, Bell DM, Culver DH, et al. Percutaneous injuries dur- ing surgical procedures. JAMA 1992; 267:2899-2904.

5. Mckenna DJ, McGlennon S, McCallum M, Dolan OM. Evaluation of a novel 'needlecatcher' surgical instrument designed to reduce the incidence of needle stick injuries from suture needles during skin suturing. Br J Dermatol 2008; 158:649-651.

6. Provenzano DA, Kamal KM, Giannetti V. Evaluation of primary care physician chronic pain management practice patterns. Pain Physician 2018; 21:E593-E602.

7. Doan L, Patel H, Aronova $\mathrm{Y}$, Gharibo C. Variations in interlaminar epidural steroid injection practice patterns by interventional pain management physicians in the United States. Pain Physician 2018; 21:E493-E499.

Appendix A. The 5-question survey.

Q1.

Do you employ any manual manipulation or "bend" at the distal tip of your spinal needle

for procedures?

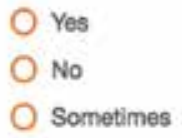

Q2.

If you place a bend on your needles, how do you employ the bend?

By hand

Using an instrument

Q3.

Have you ever suffered injury (fingerstick) while bending the spinal needle manually?

Yes

No

Q4. How long have you been practicing as an interventional pain physician?

$0-5$ years

6-10 years

(10-15 years

$\mathrm{O}>15$ years

Q5. What type of practice best represents your work setting?
Academic institution
Private practice
Hospital based practice
Multispecialty group 